\section{AS CIÊNCIAS SOCIAIS NO CURRÍCULO DO ENSINO MÉDIO BRASILEIRO}

\author{
SOCIAL SCIENCES IN THE BRAZILIAN HIGH SCHOOL CURRICULUM
}

Cristiano das Neves Bodart ${ }^{1}$

Fernanda Feijó ${ }^{2}$

\begin{abstract}
Resumo: A história da Sociologia escolar está fortemente marcada pelas mudanças curriculares do ensino secundário brasileiro, de modo que compreendê-la demanda conhecer as principais alterações curriculares nesse nível de ensino. As mudanças recentes no currículo do Ensino Médio, induzidas pela Lei n 13.415/2017 e pela nova Base Nacional Comum Curricular (2019), parecem impactar substancialmente na forma e presença que essa disciplina ganhará a partir das reformulações dos currículos estaduais iniciadas em 2019. Pela importância e urgência, aqui é examinada a BNCC, observando e discutindo como a Sociologia Escolar, a partir de suas especificidades, pode colaborar para alcançar os objetivos de aprendizagem que norteiam a legislação educacional recente. As análises das competências trazidas pela BNCC (2019) demonstram seu diálogo direto com as contribuições que as Ciências Sociais podem trazer aos alunos do Ensino Médio, evidenciando a necessidade de sua manutenção e ampliação nesse nível de ensino.
\end{abstract}

Palavras-chave: Ensino. Currículo. BNCC. Sociologia escolar.

Abstract: The history of school Sociology is strongly marked by the curricular changes in Brazilian High School education, so that understanding it requires knowing the main curricular changes at this level of education. The recent changes in the High School curriculum, induced by Law n. 13,415 / 2017 and the new Base Nacional Comum Curricular (2019), appear to substantially impact form and presence that this discipline will gain from the reformulations of the state curricula started in 2019. For the importance and urgency, the BNCC is examined here, observing and discussing how School Sociology, based on its specificities, can collaborate to achieve the learning objectives that guide recent educational legislation. The analysis of competencies brought by BNCC (2019) demonstrates its direct dialogue with the contributions that Social Sciences can bring to high school students, highlighting the need for their maintenance and expansion at this level of education.

Keywords: Teaching. Curricula. BNCC. School Sociology.

Resumen: La historia de la sociología escolar está fuertemente marcada por los cambios curriculares en la educación secundaria brasileña, por lo que comprenderla requiere conocer los principales cambios curriculares en este nivel de educación. Los cambios recientes en el plan de estudios de la escuela secundaria, inducidos por la Ley $\mathrm{N}^{\circ} 13.415$ I 2017 y la nueva Base Curricular Común Nacional (2019), parecen tener un impacto sustancial en la forma y presencia que esta disciplina obtendrá de las reformulaciones de los planes de estudio estatales iniciados en 2019. Por su importancia y urgencia, BNCC se examina aquí, observando y discutiendo cómo la Sociología Escolar, en base a sus especificidades, puede colaborar para lograr los objetivos de aprendizaje que guían la legislación educativa reciente. El análisis de competencias aportado por BNCC (2019) demuestra su diálogo directo con las contribuciones que las ciencias sociales pueden aportar a los estudiantes de secundaria, destacando la necesidad de su mantenimiento y expansión en este nivel de educación.

Palabras clave: Docencia. Plan de estudios. BNCC. Escuela de sociología.

1 Doutor em Sociologia pela Universidade de São Paulo (USP), Professor do Centro de Educação da Universidade Federal de Alagoas (UFAL). Docente do Programa de Pós-Graduação em Sociologia dessa mesma IES. E-mail: cristianobodart@gmail.com. Orcid: https://orcid.org/0000-0002-2195-2145.

2 Doutora em Ciências Sociais pela Universidade Estadual Paulista (UNESP), Professora do Centro de Educação da Universidade Federal de Alagoas (UFAL).E-mail: fernanda_feijo@yahoo.com.br. Orcid: https://orcid.org/0000-00026096-4050. 


\section{INTRODUÇÃO}

A história da Sociologia escolar está fortemente marcada pelas reformas educacionais do ensino secundário brasileiro, as quais impactam de diferentes formas, ora tornando-a obrigatória, ora optativa. Trata-se de uma disciplina com obrigatoriedade intermitente e com formas de presenças variadas. A Sociologia escolar já foi predominantemente conservadora, hoje, progressista. Já esteve presente predominantemente de forma interdisciplinar, hoje, disciplinar. Já foi de acesso restrito a uma pequena parcela da sociedade, hoje, mais acessível. Já esteve limitada à análise educacional (nos cursos normais, voltados à formação de professores primários), hoje, voltando-se a todos os fenômenos sociais de interesse docente e/ou discente. Todas essas mudanças só são passíveis de serem compreendidas a partir da análise das mudanças curriculares ocorridas nos últimos 130 anos; o que não é nosso objetivo aqui. Atualmente novas mudanças curriculares parecem impactar a forma e a presença da Sociologia escolar. É justamente olhando para o currículo que acreditamos poder compreender o "novo momento" dessa disciplina a fim de explorar de quais formas ela pode colaborar para alcançar os objetivos de aprendizagem traçados pela nova Base Nacional Comum Curricular, aprovada em 2019, documento que passa a nortear as reformulações dos currículos estaduais.

Por "Sociologia escolar", referimo-nos à disciplina de Sociologia presente no Ensino Médio, a qual envolve as três grandes áreas das Ciências Sociais, a Antropologia, a Sociologia e a Ciência Política (SANTOS, 2014). Tal disciplina vem apresentando importantes contribuições para alcançar os objetivos educacionais expressos na Lei de Diretrizes e de Base da Educação brasileira (LDB) e demais normativas curriculares, tais como as DCNEM, os PCNs e as OCEM.

Aqui realizamos uma leitura exploratória da Base Nacional Comum Curricular (BNCC) para identificar os objetivos de aprendizagem traçados e demandados a partir da Reforma do Ensino Médio (2017), expressa na Lei $n^{\circ}$ 13.415/2017. Tal análise é necessária a fim de discutir quais formatos pode a Sociologia escolar vir a ter, a fim de colaborar para atingir tais objetivos, inclusive compondo os itinerários formativos. Assim, trata-se de uma análise documental da legislação educacional historicamente produzida, bem como da recentemente instituída, seguida de reflexões propositivas ao ensino da Sociologia escolar amparadas na literatura especializada.

Pretendemos, portanto, realizar uma análise relacional das competências gerais e específicas para a área de Ciências Humanas e Sociais Aplicadas da BNCC, com foco na imprescindível colaboração da Sociologia Escolar como forma de alcançar os objetivos preconizados para o desenvolvimento do estudante do Ensino Médio. Nesse sentido, identificamos as referidas competências, uma a uma, relacionando-as às potencialidades existentes para a formação do educando a partir do corpus de conhecimento específico existente nas Ciências Socais.

Os esforços aqui apreendidos justificam-se porque a história da Sociologia escolar nos mostra que as mudanças curriculares sempre apresentam impactos na disciplina, seja em sua forma ou em sua presença no interior do currículo. Assim, compreender a reforma curricular nos auxilia no entendimento do lugar (carga-horária, se como componente básico ou complementar, etc.) e a forma (se disciplinar ou transdisciplinar) que a Sociologia escolar pode vir a tomar nos currículos estaduais, os quais estão em processo de reformulação.

Este artigo está organizado em duas partes, além desta introdução e das considerações finais. Na primeira parte é realizado um breve resgate histórico da Sociologia escolar face as reformas curriculares nacionais. Tal seção justifica-se por demonstrar os impactos das mudanças curriculares sobre a Sociologia escolar, o que nos auxilia a compreender a fragilidade da disciplina propiciada pelas constantes mudanças. Na segunda parte exploramos a reforma educacional em curso, voltando-nos à BNCC, seus objetivos de aprendizagem compostos por competências e habilidades, a fim de explorar e discutir de quais formas a Sociologia escolar pode colaborar para alcançar tais objetivos, inclusive na composição dos itinerários formativos.

\section{AS CIÊNCIAS SOCIAIS NO CURRÍCULO DO ENSINO MÉDIO BRASILEIRO}

No Brasil, a Sociologia apareceu no currículo escolar pela primeira vez no final do século XIX, podendo ser mencionados os esforços de Rui Barbosa e de Benjamin Constant como as primeiras 
tentativas de estabelecer seu ensino no Brasil (MACHADO, 1987), porém foram poucas as instituições de ensino a ofertarem a disciplina. No ano de 1916 foi aprovado um Decreto Municipal no Rio de Janeiro, de n. 1.059, de 14 de fevereiro, incluindo a disciplina "Educação Moral, Noções de Sociologia e Direito Usual" nas Escolas Normais, sendo duas (2) lições no $1^{\circ}$ ano, duas (2) no segundo, $1 / 2$ lição no terceiro e $1 / 2$ no quarto ano, totalizando cinco (5) lições ao longo do curso normal (FIGUEIREDO, 2017). Um manual homônimo à disciplina foi publicado por Figueiredo (2017), objetivando atender aos professores; contudo, não temos notícias se efetivamente a disciplina chegou a ser ofertada do Rio de Janeiro.

Em 1925, por meio do Decreto n. 16.782-A (Reforma Rocha Vaz), a Sociologia é apontada como obrigatória no $6^{\circ}$ ano (último ano) do ensino secundário do Colégio Pedro II, modelo para as demais instituições do país. Em 1931, por meio do Decreto n. 19.890, de 1931 (Reforma Francisco Campos) a Sociologia passou a ser obrigatória nos cursos complementares (de acesso ao Ensino Superior), sendo oferecida no $2^{\circ}$ ano do curso (MACHADO, 1987). Importa destacar que a presença da Sociologia no currículo secundário nos anos de 1930 e 1940 é marcada por dificuldades de definições de conteúdos e métodos de ensino, uma vez que a Reforma Rocha Vaz não apresentava nem os conteúdos a serem ensinados, nem a metodologia (GUELFI, 2001). Certamente, os manuais de Sociologia na época publicados e traduzidos para o português acabaram, em alguma medida, norteando a prática docente, porém não sendo o único orientador curricular. Como observado por Bodart e Marchiori (2016) havia uma forte presença dos princípios da carta Encíclica Rerum Novarum, do Papa Leão XIII, de 1891.

Contudo, em 1942, por meio da Reforma Capanema, mais especificamente a partir do Decreto-lei n.4.244, de 9 de abril de 1942, a Sociologia deixou de ser obrigatória no currículo do ensino secundário brasileiro. Apenas em 1971, por meio da Lei Jarbas Passarinho n. 5.692, a Sociologia voltou a ser apontada como componente curricular nesse nível de ensino, porém como optativa, juntamente com outras dezenas de disciplinas. Durante o período de 1942 aos anos de 1980 certamente a Sociologia foi ofertada como componente curricular optativo, estando presente principalmente nos cursos de formação de professores primários, voltando-se à educação, sob as nomenclaturas de Sociologia da Educação e Sociologia Educacional.

A Lei 7.044/82, que alterou a Lei 5.692/71, desobrigou a qualificação profissional compulsória no $2^{\circ}$ grau, alterando o termo "qualificação para o trabalho" para "preparação para o trabalho". Essa lei manteve, nos $1^{\circ}$ e $2^{\circ}$ graus, o currículo dividido em duas partes,

[...] um núcleo comum, obrigatório em âmbito nacional, e uma parte diversificada para atender, conforme as necessidades e possibilidades concretas, às peculiaridades locais, aos planos dos estabelecimentos de ensino e às diferenças individuais dos alunos (BRASIL, 1982, Lei 7.044/82, art.4).

A Lei 7.044/82 reabriu espaços para as disciplinas de Ciências Humanas, sem, contudo, tornar a Sociologia obrigatória. A partir daquele momento, deu-se início a um amplo movimento de reintrodução da Sociologia no Ensino Médio (MARAES, 2011; AZEVEDO, 2014).

Embora a reintrodução obrigatória da Sociologia enquanto componente curricular do Ensino Médio ${ }^{3}$ de todo o país tivesse ocorrido oficialmente em 2008, sua reintrodução deu-se gradualmente, ao longo do período que se estende de 1984 a 2008 (OLIVEIRA, 2013a; AZEVEDO, 2014). Entre 1984 a 1996, encontramos indicativos legais para a presença da Sociologia nos currículos do Ensino Médio em alguns estados brasileiros (AZEVEDO, 2014), o que não significa que a disciplina estivesse sendo ofertada em todas as escolas, ou até mesmo ofertada em alguma. Vale destacar que muitos estados, a exemplo de São Paulo, reintroduziram a Sociologia e logo a excluíram ou deixaram de cumprir as normativas que obrigavam sua oferta. A Lei Federal $\mathrm{n}^{\circ} .11 .684$ de 2008 tem sua importância justamente por tornar concreta a presença da Sociologia no Ensino Médio. Vale frisar que a obrigatoriedade da Sociologia no currículo do Ensino Médio brasileiro deu-se após muitas discussões, ações coletivas, normativas e diretrizes que foram sendo aprovadas, inclusive com caráter de "desdisciplinarização" do currículo.

3 A partir de 1996 o ensino secundário, que antes denominava-se $2^{\circ}$ grau, passou a ser intitulado Ensino Médio. 
Desde 1996, por meio da Lei de Diretrizes e Bases da Educação Brasileira (LDB 9394/96), os saberes sociológicos passaram a ser, de algum modo, mencionados como necessários ao projeto educacional que se desenhava no país. A LDB, quando aprovada, trouxe tais saberes como importantes para a formação da cidadania, um dos principais objetivos da lei. Contudo, esse indicativo não foi suficiente para reintroduzir a Sociologia no currículo do ensino secundário. Nele, em seu artigo $36, \S 1^{\circ}$, encontrávamos a seguinte orientação:

Os conteúdos, as metodologias e as formas de avaliação serão organizadas de tal forma que ao final do ensino médio o educando demonstre: [...] III - domínio dos conhecimentos de Filosofia e Sociologia necessários ao exercício da cidadania.

O Parecer CNE/CEB 05/97 já destacava a dúvida que poderia surgir na interpretação do trecho em relação à Sociologia no Ensino Médio, afirmando ser necessário antecipar "a dúvida que será levantada nos sistemas de ensino e nas instituições que os integram, quanto à forma a ser adotada, visando ao ‘domínio dos conhecimentos de Filosofia e Sociologia"'. Como destacou Oliveira:

[...] o impacto mais signficativo dessas Diretrizes sobre o Ensino de Sociologia, que foi a compreensão de que a referida disciplina deveria ser lecionada de forma "interdisciplinar", desconsiderando aí as particularidades teóricas e metodológicas presentes na construção do saber sociológico (2014, p. 643).

Em 1998, buscando apresentar novas orientações aos entes federativos, foi aprovado o Parecer CNE/CEB 15/98, dando margem a compreensão de que a Sociologia poderia ser ensinada de forma transdisciplinar. No mesmo ano, uma resolução foi aprovada (CNE/CEB 03/98 1998b), indicando em seu artigo 10, " $\$ 2^{\circ}$, que "as propostas pedagógicas das escolas deverão assegurar tratamento interdisciplinar e contextualizado para: [...] b) Conhecimentos de Filosofia e Sociologia necessários ao exercício da cidadania".

Tanto a LDBEN (1996), quanto os Parâmetros Curriculares Nacionais para o Ensino Médio (PCNEM), lançados em 2000, vão apontar para um currículo interdisciplinar, embora tenha encontrado resistência por aqueles que defendiam um currículo disciplinar, como bem apontou Moraes:

[...] se observarmos bem as DCNEM, a ideia que a condicionou era a da interdisciplinaridade, ou da "desdisciplinarização". A definição por áreas de conhecimento representava certa dificuldade de conceber um currículo totalmente interdisciplinar, ou uma concessão às pressões da equipe que formulava os Parâmetros Curriculares Nacionais do Ensino Médio (PCNEM) e que tinha seus membros recrutados nas sociedades científicas, ciosas das suas especificidades e de seus espaços no currículo (Moraes, Tomazi \& Guimarães, 2004), razão pela qual estes Parâmetros acabaram permanecendo disciplinares, incluindo os PCNEM de Filosofia e Sociologia (Sociologia, Antropologia e Política) (2011, p. 371).

A visão voltada a um currículo interdisciplinar levou à interpretação de que a Sociologia poderia estar presente enquanto saberes e práticas no interior das "Ciências Humanas e suas tecnologias", embora encontrássemos nos PCN de Ciências Humanas e suas Tecnologias uma seção voltada ao ensino de Sociologia, Antropologia e Política, inclusive reconhecendo suas importâncias. Contudo, o documento não indicava que o currículo estivesse obrigatoriamente organizado de forma disciplinar (PCN, 2000).

Os PCN+ (2002), buscando apresentar maiores detalhes orientacionais, voltou a reforçar o caráter interdisciplinar e transdisciplinar que o currículo deveria possuir, inclusive aprofundando a adesão à Pedagogia das Competências - já presente na DCNEM (1996) -, pondo em xeque a definição de conteúdos: "ao invés de transmissão, aquisição ou até mesmo de construção de conhecimentos [...], o que passou a dominar o discurso pedagógico, de que as Diretrizes são um exemplar fiel, foi o "desenvolvimento de competências e habilidades" (MORAES, 2011, p. 371). O ensino-aprendizagem voltado ao "desenvolvimento de competências e habilidades" colaborou para o aprofundamento de um currículo interdisciplinar, presente na atual proposta da BNCC (2019), assim como a mudança na LDB, com a Lei 13415/17, que retirou a obrigatoriedade nominal disciplinar da Sociologia, limitando-se a indicar ser obrigatório a presença de seus saberes e de suas práticas.

Paralelamente à publicação desses parâmetros curriculares, encontramos uma mobilização 
crescente em defesa da presença da Sociologia enquanto corpo disciplinar obrigatório e expresso nominalmente na LDB. Ainda que não fosse comum indicação nominal de obrigatoriedade de disciplina na referida lei, sua falta de tradição enquanto componente curricular obrigatório era visto como uma forma de encerrar de vez as discussões em torno da forma como estaria presente no Ensino Médio.

Em 17 de junho de 1997, dá-se início à tramitação do Projeto de Lei 3.178/97, que visava alterar a LDB, incluindo em seu artigo 36 o seguinte trecho: "IV - Serão incluídas a Filosofia e a Sociologia como disciplinas obrigatórias". A justificativa para a inclusão estava no reconhecimento de que a disciplinarização curricular era importante. Segundo a proposta de lei, "dificilmente será bem sucedida a inclusão de temas referentes a estes campos em outras disciplinas, com docentes que não tenham a formação plena e adequada para o cumprimento dessa tarefa. Daí ser insatisfatório o texto da atual LDB" (Projeto de Lei 3.178/97). No parecer dado pelo relator do referido Projeto de Lei encontramos o seguinte trecho: "Concordamos com o autor da proposição de que o atual texto da LDB é insatisfatório, pois fala vagamente em 'domínio dos conhecimentos de Filosofia e de Sociologia...' (art. $36, \S 1^{\circ}$, inciso III)" (Parecer do Projeto de Lei 3.178/97). Em 22 de setembro de 1999, o Projeto de Lei foi aprovado no Congresso Nacional, porém em 08 de outubro de 2001 foi vetado pelo presidente da República sob o argumento de não ter profissionais suficientes para a demanda que surgiria com a obrigatoriedade da disciplina, bem como a ampliação dos gastos dos entes federativos com a contratação de mais professores. Nota-se que o veto não tem relação com aspectos pedagógicos, nem são refutados os argumentos presentes na proposta. Em 07 de julho de 2001 o Congresso Nacional acatou o veto presidencial e a Sociologia naquela ocasião não foi incluída como componente curricular obrigatório.

As disputas entre uma perspectiva disciplinar e interdisciplinar estenderam-se pelos anos seguintes. Em 2006 foram aprovadas as Orientações Curriculares para o Ensino Médio (OCEM), trazendo um avanço fundamental para a posterior afirmação da presença da Sociologia no currículo, assim como orientações epistemológicas (os princípios epistemológicos) importantes à sua prática, indicando o papel da Sociologia no processo de desnaturalização e estranhamento da realidade social e como isso poderia ser operacionalizado a partir dos princípios metodológicos de ensino, os quais poderiam dar-se por meio da pesquisa, de temas, de teorias ou de conceitos sociológicos. Nesse mesmo ano, o CNE aprovou parecer (n.38/06) favorável a introdução da Sociologia como componente disciplinar do currículo do Ensino Médio e a Resolução n. 04/06, que a tornava obrigatória nos currículos disciplinares. Embora não tendo força de lei, colaborou para que a proposta de indicação nominal da obrigatoriedade da Sociologia na LDB se materializasse em 2008, por meio da Lei $n^{\circ} 11.684$.

Nota-se que as normativas e diretrizes publicadas até 2008 não foram suficientes para incluir a Sociologia como componente disciplinar obrigatório no Ensino Médio. Somente com a publicação da Lei $n^{\circ} 11.684$ houve a alteração da LDB, a qual passou a ter, em seu artigo 36, a seguinte redação: "serão incluídas a Filosofia e a Sociologia como disciplinas obrigatórias em todas as séries do Ensino Médio". A partir desse momento, a Sociologia passou a estar presente em todas as redes de Ensino Médio do país e galgando espaços em programas governamentais importantes, tais como o Plano Nacional do Livro Didático (2012, 2015 e 2018), o Programa Institucional de Bolsa de Iniciação à Docência (PIBID) (2009-2020) e, recentemente, a Residência Pedagógica (2019-2020), assim como fomentando a ampliação das pesquisas sobre o ensino de Sociologia (BODART; CIGALES, 2017; BODART; TAVARES, 2020), as quais são fundamentais para a qualificação da prática docente, da formação de professores e do currículo. As discussões em torno do currículo de Sociologia expandiram-se sobremaneira a partir da reintrodução da Sociologia. Enquanto os debates antes da reintrodução da disciplina, em 2008, centravam-se prioritariamente na institucionalização da Sociologia no ensino básico, a partir desse momento as preocupações voltaram-se, em grande medida, para o currículo e a prática docente (BODART; CIGALES, 2017; BODART; TAVARES, 2020).

Contudo, a Reforma do Ensino Médio, expressa na Lei n 13.415, de 16 de fevereiro de 2017, fragilizou a permanência da Sociologia nesse nível de ensino, uma vez que passou a trazer na LDB que caberia à Base Nacional Comum Curricular (BNCC) referente ao Ensino Médio incluir "obrigatoriamente estudos e práticas de [... ] Sociologia e Filosofia” (BRASIL- LDB, art. 35-A, § 2). A BNCC para o Ensino Médio traz em 
seu texto que Sociologia e Filosofia integram, juntamente com Geografia e História, a área de "Ciências Humanas e Sociais Aplicadas", sem, contudo, apresentar detalhes sobre como a Sociologia deverá figurar nos currículos estaduais. A impressão que temos é que vivenciamos um retrocesso aos debates que pareciam ter sido superados em 2008, voltando à visão de "desdisciplinarização" do currículo, sendo a Sociologia uma das "vítimas" desse processo (juntamente com Filosofia, Artes e Educação Física) por sua falta de tradição no interior do currículo obrigatório nacional e pela fragilidade de sua presença, marcada pelo preconceito, pela reduzida carga-horária e pelo fato de que a grande maioria dos professores que a lecionam o fazem como forma de complementar sua carga-horária de trabalho (BODART; SAMPAIOSILVA, 2019). O debate atual em torno da permanência da Sociologia e o tamanho de carga-horária darse-á junto às Secretarias Estaduais de Educação que estão - orientadas pela BNCC - no esforço de realizar a restruturação curricular.

\section{A BASE NACIONAL COMUM CURRICULAR (BNCC) E AS CIÊNCIAS SOCIAIS}

A BNCC abre lacunas para incertezas que impactam sobremaneira a forma e a presença da Sociologia - e também as demais disciplinas escolares - no currículo, isso por não apresentar nominalmente os componentes curriculares (com exceção de Língua Portuguesa e Matemática), mas apenas a áreas de conhecimento, aspecto gestado nas diretrizes curriculares, pós LDB (1996). Sendo, atualmente, a principal referência curricular para o Ensino Médio brasileiro, importa compreender o papel e lugar do ensino da Sociologia no documento. Para tanto, analisamos as principais competências presentes na BNCC, tanto no documento geral quanto no específico à área de Ciências Humanas e Sociais Aplicadas. Antes disso, faz-se necessária uma rápida discussão acerca da relação entre BNCC e Reforma do Ensino Médio.

\subsection{A Reforma do Ensino Médio e o ensino das Ciências Sociais}

O documento da BNCC está atrelado à realização da Reforma do Ensino Médio promovida pelo governo de Michel Temer (2016-2018) por meio, inicialmente, da Medida Provisória (MP) 746/16, que deu origem à Lei $13.415 / 17^{4}$. Porém, as mudanças no Ensino Médio já vinham sendo debatidas no governo Dilma Roussef (2011-2016), tendo sido uma proposta de reforma discutida pela Comissão Especial da Câmara dos Deputados destinada a promover Estudos e Proposições para a Reformulação do Ensino Médio (CEENSI) por meio do PL 6840/135. Essa primeira proposta de Reforma é, em alguma medida, parecida com a aprovada em 2017, sobretudo no que tange à ideia de uma educação de tempo integral ao propor aumento de carga horária - e também na divisão dos itinerários formativos ${ }^{6}$ (que são os mesmos em ambos os Projetos). Tais mudanças remontam a ideias do projeto educacional de desdisciplinarização existente desde o final dos anos de 1990.

O PL6840/13 foi amplamente debatido e passou por várias audiências públicas e devido à grande contraposição de parte da classe política e de entidades da Sociedade Civil, o projeto acabou não sendo encaminhado para votação no governo de Dilma Rousseff. Com o processo de impeachment e a consequente posse de Michel Temer, novos encaminhamentos visaram atender aos anseios de grupos de interesse (sobretudo da educação privada) que solicitavam a aprovação das mudanças no Ensino Médio (CORTI, 2019). A Reforma foi inicialmente implementada por meio de uma Medida Provisória (MP746/16), medida considerada autoritária (CORTI, 2019; FERRETTI, 2018; FERREIRA, SANTANA, 2018), tendo em vista que uma reforma de amplas proporções deveria ter sido amplamente discutida com educadores, professores, gestores e pesquisadores, antes de ser aprovada.

4 Conhecida como Lei da Reforma do Ensino Médio, traz alterações à Lei de Diretrizes e Bases da Educação (LDB 9394/96), ao Fundo de Manutenção e Desenvolvimento da Educação Básica e Valorização dos Profissionais da Educação (FUNDEB) e Consolidação das Leis do Trabalho (CLT). Pode ser vista na íntegra em: https://legis.senado.leg.br/norma/602639/publicacao/15657824. Acesso em: 12/03/2017.

50 Projeto de Lei pode ser consultado na íntegra no endereço https://www.camara.leg.br/proposicoesWeb/fichadetramitacao?idProposicao=602570. Acesso em: 05/12/2016 6 São cinco os itinerários formativos propostos pela Reforma do Ensino Médio: Linguagens e suas Tecnologias, Matemática e suas Tecnologias, Ciências da Natureza e suas Tecnologias, Ciências Humanas e Sociais Aplicadas e Formação Técnica e Profissional. 
A principal justificativa para a aprovação de urgência da Reforma baseava-se no discurso de que era preciso resolver os graves problemas do Ensino Médio brasileiro. Segundo Corti:

\begin{abstract}
O discurso a respeito da baixa performance de alunos em sistemas de avaliação de larga escala é recorrentemente utilizado para justificar a necessidade de reformas educacionais. Trata-se de uma tendência global, fortalecida com a criação do Programa Internacional de Avaliação de Estudantes (PISA) pela Organização para a Cooperação e Desenvolvimento Econômico (OCDE) em 2000, ao qual o Brasil aderiu desde sua primeira edição (CORTI, 2019, p.5).
\end{abstract}

Outra justificativa bastante divulgada pelo Ministério da Educação à época da aprovação da Medida Provisória (MP) estava na necessidade de tornar o Ensino Médio atrativo para o aluno, o que se daria através da flexibilização do currículo (FERRETTI, 2018). A Reforma não toca nas questões mais urgentes e estruturais, nem no fato de que muitos jovens deixam a escola para trabalhar, tornando-a insuficiente. Ou seja, não tratou daquilo que seria fundamental reformar: questões estruturais, como melhores condições de trabalho para os professores, instalações adequadas nas escolas (salas de aula, informática, biblioteca, etc), número de alunos em sala de aula ${ }^{7}$, etc.

A Reforma limitou-se a flexibilização do currículo e ao ensino de tempo Integral. Na tentativa de tornar o currículo mais atraente, a Reforma permite que os alunos, após cursarem as disciplinas obrigatórias pela $\mathrm{BNCC}^{8}$ (1800 horas no máximo) complementem sua formação, optando por um dos 5 itinerários formativos ${ }^{9}$ a serem oferecidos. A problemática desse formato encontra-se no acesso fragmentado à diversidade de produção científica, havendo o risco do estudante não ter condições de obter uma formação com acesso aos diversos conhecimentos produzidos (FERRETTI, 2018).

Além do problema de não ter sido amplamente discutida, a Reforma do Ensino Médio trouxe uma grave alteração na distribuição disciplinar no currículo escolar ao estabelecer a tal "flexibilização": somente as disciplinas de Língua Portuguesa e Matemática passam a ser obrigatórias nas três séries do Ensino Médio ${ }^{10}$. Não existe a indicação de que outras disciplinas sejam obrigatórias no currículo. Esse contexto gerou inquietação entre pesquisadores, professores e entusiastas da Sociologia Escolar, já que sua obrigatoriedade está ameaçada.

Após a manifestação pública de diversas entidades e instituições ligadas à Educação, à Filosofia e às Ciências Sociais a Lei 11.3415/17 incorporou a presença de "saberes e práticas" de Filosofia e Sociologia (além de Educação Física e Artes) como forma de demonstrar que tais conhecimentos ainda poderiam estar presentes no Ensino Médio, porém, não garantindo a presença dessas disciplinas, o que mantém a comunidade em torno do subcampo de pesquisa de Ensino de Sociologia em alerta.

No final de 2019, a BNCC para o Ensino Médio foi homologada pelo CNE e aprovada definitivamente, sendo ela resultado de um processo que tem sua origem, ao menos, em 2011, tendo passado por três versões. As duas primeiras, como destacaram Silva, Alves Neto e Vicente (2015), foram marcadas por significativa participação de diversos representantes da sociedade civil, entidades e universidades. Estas apresentavam os componentes curriculares com suas especificidades teórico-metodológicas. Contudo, a terceira versão apresentou um rompimento importante em relação as propostas presentes nos documentos anteriores, sendo resultado da Reforma do Ensino Médio de aprovação aligeirada e com abertura participativa duvidosa, que retomou com maior força a ideia de um currículo por competências e desdisciplinarizado (AGUIAR, 2018).

Como resultado desse conturbado processo de construção da BNCC, temos as disciplinas dissolvidas em áreas do conhecimento - somente Português e Matemática aparecem como disciplinas

7 Segundo pesquisa da OCDE quanto menor o número de alunos em sala, maior o rendimento escolar. Para mais informações ver: http://www.oecd.org/education/. Acesso em 10/03/2020

8 A BNCC será discutida na subseção a seguir.

9 Ver nota de rodapé número 3.

10 Posteriormente a Língua Inglesa (Como Língua Estrangeira Moderna) também foi incluída como disciplina obrigatória. 
autônomas - de modo que o currículo fica organizado a partir das competências indicadas como necessárias para o desenvolvimento dos alunos do Ensino Médio. Tal modelo, como já indicado, dialoga diretamente com as políticas educacionais na década de 1990, e desconsidera a relevância da especificidade e autonomia presente em cada uma das disciplinas como parte de um todo dentro do processo de investigação científica.

Apesar disso, podemos observar que reorganizações curriculares nos estados (temos contato com pesquisadores que acompanham o processo em São Paulo, Bahia, Minas Gerais, Alagoas, Ceará, dentre outros) já acenam para a manutenção - ainda que mínima - da Sociologia nos currículos; em alguns casos a carga-horária sendo mantida, em outros reduzida ou ampliada. A questão agora é pensar a carga horária da disciplina ${ }^{11}$ e como ela pode auxiliar para promover as competências exigidas pela BNCC, inclusive para os Itinerários Formativos. A Reforma está posta, não será fácil revertê-la a curto e médio prazo. Precisamos, portanto, compreender em que medida as Ciências Sociais inserem-se nesse novo cenário, buscando colaborar para que os aspectos negativos dessa nova política educacional sejam mitigados.

\subsection{A presença das Ciências Sociais nas Competências da BNCC}

Sob as indicações da BNCC, os estados já estão encaminhando suas propostas para audiências públicas. Torna-se necessário discutir de quais maneiras o ensino de Sociologia colabora para a qualificação da educação no contexto da BNCC. Nesse sentido, analisamos como as Ciências Sociais dialogam com as competências estabelecidas na Base, de modo a demonstrar que a Sociologia, enquanto componente curricular, é de suma importância para a formação do estudante do Ensino Médio. Iniciaremos nossa análise pelas competências gerais da BNCC para a Educação Básica.

\section{Quadro 1 - Competências Gerais indicadas Base Nacional Comum Curricular (2019).}

1 - Valorizar e utilizar os conhecimentos historicamente construídos sobre o mundo físico, social, cultural e digital para entender e explicar a realidade, continuar aprendendo e colaborar para a construção de uma sociedade justa, democrática e inclusiva.

2 - Exercitar a curiosidade intelectual e recorrer à abordagem própria das ciências, incluindo a investigação, a reflexão, a análise crítica, a imaginação e a criatividade, para investigar causas, elaborar e testar hipóteses, formular e resolver problemas e criar soluções (inclusive tecnológicas) com base nos conhecimentos das diferentes áreas.

3 - Valorizar e fruir as diversas manifestações artísticas e culturais, das locais às mundiais, e também participar de práticas diversificadas da produção artístico-cultural.

4 - Utilizar diferentes linguagens - verbal (oral ou visual-motora, como Libras, e escrita), corporal, visual, sonora e digital -, bem como conhecimentos das linguagens artística, matemática e científica, para se expressar e partilhar informações, experiências, ideias e sentimentos em diferentes contextos e produzir sentidos que levem ao entendimento mútuo.

5 - Compreender, utilizar e criar tecnologias digitais de informação e comunicação de forma crítica, significativa, reflexiva e ética nas diversas práticas sociais (incluindo as escolares) para se comunicar, acessar e disseminar informações, produzir conhecimentos, resolver problemas e exercer protagonismo e autoria na vida pessoal e coletiva.

6 - Valorizar a diversidade de saberes e vivências culturais e apropriar-se de conhecimentos e experiências que lhe possibilitem entender as relações próprias do mundo do trabalho e fazer escolhas alinhadas ao exercício da cidadania e ao seu projeto de vida, com liberdade, autonomia, consciência crítica e responsabilidade.

7 - Argumentar com base em fatos, dados e informações confiáveis, para formular, negociar e defender ideias, pontos de vista e decisões comuns que respeitem e promovam os direitos humanos, a consciência socioambiental e o consumo responsável em âmbito local, regional e global, com posicionamento ético em relação ao cuidado de si mesmo, dos outros e do planeta.

$11 \mathrm{O}$ ideal é os alunos tenham acesso à Sociologia ao longo de todas as séries do Ensino Médio, com uma cargahorária que possibilite aos professores ofertar um ensino com qualidade.

Rev. Espaço do Currículo (online), João Pessoa, v.13, n.2, p. 219-234, maio/agos. 2020. 
ISSN 1983-1579

Doi: 10.22478/ufpb.1983-1579.2020v13n1.51194

http://periodicos.ufpb.br/ojs2/index.php

8 - Conhecer-se, apreciar-se e cuidar de sua saúde física e emocional, compreendendo-se na diversidade humana e reconhecendo suas emoções e as dos outros, com autocrítica e capacidade para lidar com elas.

9 - Exercitar a empatia, o diálogo, a resolução de conflitos e a cooperação, fazendo-se respeitar e promovendo o respeito ao outro e aos direitos humanos, com acolhimento e valorização da diversidade de indivíduos e de grupos sociais, seus saberes, identidades, culturas e potencialidades, sem preconceitos de qualquer natureza.

10 - Agir pessoal e coletivamente com autonomia, responsabilidade, flexibilidade, resiliência e determinação, tomando decisões com base em princípios éticos, democráticos, inclusivos, sustentáveis e solidários.

Fonte: Base Nacional Comum Curricular (BNCC), Ministério da Educação, 2019a.

A primeira competência versa sobre a valorização e utilização dos conhecimentos sobre o mundo social e cultural para entender e explicar a realidade. Com relação a isso, mencionamos a contribuição da Sociologia Escolar para a realização desse objetivo, tendo em vista o vasto campo de desenvolvimento de teorias acerca do mundo social e cultural passíveis de serem utilizados. Conforme apontam Bauman e May (2010), a Sociologia leva-nos a refletir sobre o mundo em que vivemos e questões que nos cercam, possibilitando a capacidade analítica da vida social para além do cotidiano e do senso comum. Essa contribuição sociológica abarca também os objetivos da segunda competência, uma vez que as Ciências Sociais podem dotar os estudantes do Ensino Médio de ferramentas para uma análise científica crítica, reflexiva e criativa acerca dos fenômenos sociais. Já no ano de 1954, Florestan Fernandes (1976) apontava a contribuição da Sociologia Escolar enquanto instrumentos de análise objetiva da realidade social, dotando os alunos de competências básicas para romper com a visão estática e dramática da vida social, proporcionando condições para a vigilância intelectual baseada no espírito crítico (FERNANDES, 1976). Como destacou Lahire (2014), a Sociologia pode promover hábitos intelectuais fundamentalmente ligados às ciências da sociedade, tornando a busca pela compreensão da realidade social uma prática cotidiana.

A terceira competência, destacada no quadro, versa sobre a capacidade de valorizar e fruir as diversas manifestações artísticas e culturais e participar de variadas práticas culturais. Acreditamos que tal competência só é alcançada a partir da compressão do conceito antropológico de cultura e da capacidade de realizar a objetivação etnográfica, atitude que o ensino de Sociologia pode promover, como destacou Lahire (2014).

A quarta competência, por sua vez, relaciona o (re)conhecimento e a utilização de diferentes linguagens a fim de ser capaz de "expressar e partilhar informações, experiências, ideias e sentimentos em diferentes contextos e produzir sentidos que levem ao entendimento mútuo" (BNCC, 2019). A contribuição da Sociologia Escolar pode ser exemplificada no desenvolvimento de melhores condições para expressarse através da escrita, uma vez que são "claras as possibilidades que o conhecimento abarcado pela Sociologia no Ensino Médio tem de subsidiar a produção da redação no ENEM" (ROGÉRIO; OLIVEIRA, 2019, p. 41). Alves e Röwer (2018) demonstram a contribuição para o desenvolvimento da expressão de ideias, sentimentos e percepções, o que se deu do desenvolvimento de competências para a produção de narrativas autobiográficas (ALVES; RÖWER, 2018).

A quinta competência versa sobre a necessidade de proporcionar condições do aluno em "compreender, utilizar e criar tecnologias digitais de informação e comunicação de forma crítica, significativa, reflexiva e ética" (BNCC, 2019). Nesse ponto há duas contribuições significativas da Sociologia Escolar: produzir e interpretar dados. O professor, tendo acesso a um laboratório de informática, pode apresentar aos alunos (e utilizar junto com eles) diversas ferramentas tecnológicas utilizadas nas Ciências Sociais. Para isso, há bases de dados de acesso aberto que podem ser exploradas, bem como softwares e programas de coletas e análise de dados mais simples, possíveis de serem manuseados por leigos, tais como formulários/survey online, planilhas de sistematização de dados, programas de coletas de temas nas redes sociais, de produção de mapas, gráficos, fluxogramas, cartogramas, cronologias, grafos, marcações de trajetórias de migrações, infográficos, cronologias sobre mapas, monitoramento de redes sociais, etc. Todas essas ferramentas são passíveis de serem 
introduzidas nas aulas de Sociologia, sobretudo se o professor propuser ensinar como o conhecimento é produzido.

A sexta competência nos remete ao "exercício da cidadania", presente na legislação educacional desde a LDB (1996). Nesse caso, a cidadania deve ser orientada para uma vivência integral que possa valorizar a diversidade e levar o jovem a assumir sua responsabilidade diante da coletividade. $O$ reconhecimento da importância da Sociologia Escolar na contribuição de uma formação cidadã esteve presente nos discursos parlamentares nos anos anteriores a sua inclusão obrigatória no Ensino Médio, tendo sido por duas vezes aprovadas pelos parlamentares (2001 e 2008) (AZEVEDO; NASCIMENTO, 2015). Como demonstraram Mota (2005), Oliveira e Engerroff (2020), o ensino de Sociologia esteve nas últimas décadas fortemente associada a cidadania ${ }^{12}$, sendo apontada como um dos principais objetivos da formação propiciada por essa disciplina. Estudos da área da Sociologia e da Ciência Política nos apontam caminhos para o debate a respeito da cidadania ativa como forma de convívio com a diversidade e exercício da tolerância, sendo uma possibilidade para a realização dos objetivos dessa competência.

A sétima competência aponta para a valorização e o respeito aos direitos humanos, temática importante nas Ciências Sociais, que perpassa grande parte dos estudos sociológicos, e pode estar presente em vários momentos das aulas de Sociologia, tais como em debates sobre cidadania, diversidade de gênero e étnico-cultural, movimentos sociais, políticas públicas, regimes políticos, etc. Como bem destacaram Oliveira e Carneiro (2017), a Sociologia Escolar tem potencialidades que, se exploradas adequadamente, contribuem para a promoção de valores relacionados aos Direitos Humanos, assim como efetivar uma Educação que envolve diversas outras competências presentes na BNCC, inclusive a oitava competência, diretamente ligada a essa questão, ao tratar do reconhecimento das diferenças e respeito à diversidade humana. Nesse sentido, a Antropologia (mas não só) tem muito a acrescentar por meio dos estudos da cultura e da vivência de costumes em suas várias formas e possibilidades, apontado para a convivência pacífica entre o eu e os outros. A alteridade é uma postura fomentada pela Sociologia Escolar (OLIVEIRA; CARNEIRO, 2017), o que ocorre ao despertar os estudantes para um olhar de estranhamento do familiar ou de familiarização do diferente, como indicado por Lahire (2014). Dentro desse contexto encontra-se também a competência número nove, que traz a necessidade do diálogo e do respeito, aspectos nos quais em muito a Sociologia Escolar pode colaborar (LAHIRE, 2014), como já destacado.

Por fim, a última competência geral traz alusão à tomada de decisões e ações com base no comportamento democrático. Feijó (2019) nos demonstra a relevância do ensino das Ciências Sociais na formação democrática do educando, o que assegura a realização das competências anteriores, ao possibilitarmos a construção de valores de tolerância e combate aos preconceitos, contrapondo-os ao senso comum. A Sociologia Escolar qualifica-se ao buscar explicações racionais para os fenômenos e fazer análises políticas por meio da ciência, colaborando para que os estudantes tornem-se "indivíduos mais preocupados com a coletividade e os problemas sociais com os quais nos confrontamos cotidianamente, de modo que possam desenvolver valores democráticos efetivos e colaborar para a valorização do bem comum" (FEIJÓ, 2019, p. 112).

A seguir, prosseguiremos com a análise das 6 competências da área de Ciências Humanas e Sociais Aplicadas. Não é possível pensar o desenvolvimento de nenhuma delas sem um currículo disciplinar. Ou seja, ainda que a BNCC traga o conhecimento por área de conhecimento, ao realizarmos a análise das competências, fica clara a necessidade do conhecimento disciplinar e autônomo de cada uma das Ciências que compõe a área. No quadro 2, apresentamos as competências específicas da área.

Quadro 2 - Competências específicas de Ciências Humanas e Sociais Aplicadas (BNCC, 2019).

\begin{tabular}{|l|l|}
\hline 1 & $\begin{array}{l}\text { Analisar processos políticos, econômicos, sociais, ambientais e culturais nos âmbitos local, regional, } \\
\text { nacional e mundial em diferentes tempos, a partir da pluralidade de procedimentos epistemológicos, } \\
\text { científicos e tecnológicos, de modo a compreender e posicionar-se criticamente em relação a eles, } \\
\text { considerando diferentes pontos de vista e tomando decisões baseadas em argumentos e fontes de } \\
\text { natureza científica. }\end{array}$
\end{tabular}

12 Vale frisar que não há um conceito universal de cidadania. 


\begin{tabular}{|l|l|}
2 & $\begin{array}{l}\text { Analisar a formação de territórios e fronteiras em diferentes tempos e espaços, mediante a compreensão } \\
\text { das relações de poder que determinam as territorialidades e o papel geopolítico dos Estados-nações. }\end{array}$ \\
\hline 3 & $\begin{array}{l}\text { Analisar e avaliar criticamente as relações de diferentes grupos, povos e sociedades com a natureza } \\
\text { (produção, distribuição e consumo) e seus impactos econômicos e socioambientais, com vistas à } \\
\text { proposição de alternativas que respeitem e promovam a consciência, a ética socioambiental e o } \\
\text { consumo responsável em âmbito local, regional, nacional e global. }\end{array}$ \\
\hline 5 & $\begin{array}{l}\text { Analisar as relações de produção, capital e trabalho em diferentes territórios, contextos e culturas, } \\
\text { discutindo o papel dessas relações na construção, consolidação e transformação das sociedades. }\end{array}$ \\
\hline 6 & $\begin{array}{l}\text { Identificar e combater as diversas formas de injustiça, preconceito e violência, adotando princípios éticos, } \\
\text { democráticos, inclusivos e solidários, e respeitando os Direitos Humanos. } \\
\text { alinhadas ao exercício da cidadania e ao seu projeto de vida, com liberdade, autonomia, consciência crítica } \\
\text { e responsabilidade. }\end{array}$ \\
\hline
\end{tabular}

Fonte: Base Nacional Comum Curricular (BNCC), Ministério da Educação, 2019.

A primeira competência específica já demonstra o quanto a Sociologia é necessária no currículo do Ensino Médio. Analisar processos econômicos, políticos, culturais e sociais é tarefa do ensino das Ciências Sociais. Além disso, a Sociologia, conforme demonstrou Wright Mills (1965), permite a compreensão da relação indivíduo-sociedade, estabelecendo explicação mais direta do que ocorre entre cada um de nós e a organização da sociedade mais ampla, estabelecendo a ligação entre a biografia, a história e entre ambas.

Importa ressaltar a presença dos conhecimentos da Antropologia e da Ciência Política (além da Sociologia) na consolidação dos objetivos propostos pelas Competências elencadas. A segunda competência demanda o desenvolvimento de conhecimentos próprios da Sociologia Política e da Ciência Política, tais como as relações de poder. Feijó (2020) chama-nos a atenção para a relevância de uma educação política para os estudantes do Ensino Médio e de como a Sociologia Escolar pode ser uma ferramenta privilegiada nesse processo. Nesse sentido, a disciplina provoca o pensar sobre questões institucionais articuladas nas ações políticas dos Estados, compreendendo suas dimensões mais subjetivas nas quais se encontram as relações entre Estado e sociedade civil, a disposição dos agentes e como estes se portam no jogo político.

A Antropologia ajuda-nos no desenvolvimento da tolerância e do respeito às diferenças quando focamos em seus estudos sobre cultura. Cabe ressaltar, conforme nos alerta Oliveira (2013), que muitos temas relevantes da Antropologia podem ser explorados no Ensino Médio, mas que ainda são marginais. Como relação a terceira competência, destacamos a relevância dos estudos culturais para compreender a complexa relação entre homem e natureza e seus desdobramentos ontológicos. Além disso, Oliveira aponta a relevância dos estudos sobre a cultura, pois,

[...] ao estudarmos outras culturas somos levados a uma melhor compreensão da nossa, redimensionando-a. [...] trazendo uma substancial contribuição teórica para a formação do aluno do Ensino Médio, como também através da realização de aulas de campo, apresentando aos alunos a metodologia própria da Antropologia, pois afinal, a pesquisa mostra-se como uma importante ferramenta pedagógica para o Ensino de Sociologia [...] (OLIVEIRA, 2013, p.11).

Podemos perceber a contribuição da Sociologia em sala de aula para a quarta competência, ao levar os alunos a compreenderem as diferentes relações sociais dentro de diferentes contextos [inclusive nas relações de trabalho], valorizando a noção de alteridade e diversidade (OLIVEIRA; CARNEIRO, 2017). Além disso, tal competência também remete aos estudos da Sociologia do Trabalho que, segundo Coan (2006) podem ser tratados no Ensino Médio a partir de múltiplas percepções teórico-metodológicas, como o seu sentido geral e ontológico, pensado como uma necessidade humana. Certamente as Ciências Sociais trazem ainda enorme gama de possibilidades de debates em sala sobre a relação entre produção, capital e trabalho, basta notar as diversas indicações presentes nos livros didáticos aprovados pelo PNLD (2018). 
A quinta e a sexta competências nos remetem, como nas gerais, à valorização dos direitos humanos e de comportamentos democráticos a partir de uma formação voltada ao exercício da cidadania. Importa destacar que a Sociologia possui especificidades para o desenvolvimento de tais competências, uma vez que:

[...] é capaz de dar um tipo de esclarecimento para os indivíduos que pode reforçar sua liberdade de escolha e aprimorar a sua compreensão sobre o mundo ao promover a autonomia e a liberdade, enfocando a autoconsciência e a responsabilidade individuais (FEIJÓ, 2019, p. 106).

A partir do desenvolvimento dessas competências, o indivíduo pode perceber qual seu papel na coletividade reconhecendo ser necessário conhecimento para usar positivamente sua liberdade, ou seja, o seu uso para o exercício da tolerância e do respeito ao outro.

Nesse sentido, a Sociologia Escolar é uma rica ferramenta para romper com concepções indesejáveis em uma democracia, ao privilegiar conhecimentos que possam despertar valores comunitários (FEIJÓ, 2019). Além disso, um ensino com essa perspectiva abre caminhos para demonstrar aos alunos que eles podem buscar espaços de empoderamento ao valorizar a coletividade, incentivandoos a abrir novas possibilidades de participação na vida política.

Para finalizar essa análise, cabe ressaltar que as competências trazidas na BNCC precisam dos conhecimentos específicos das disciplinas escolares para serem apropriadamente promovidas. Nossas análises voltaram-se às potencialidades das Ciências Sociais na formação do aluno do Ensino Médio, seja nas questões de cidadania, tolerância, análise de fenômenos sociais, conhecimento e reconhecimento da cultura, desenvolvimento da alteridade e apreço pela democracia, direitos humanos, compreensão de que é resultado de ações coletivas, dentre muitos outros conteúdos fundamentais para desenvolver o conhecimento necessário à compreensão e reflexão crítica da realidade social que os cerca. Fernandes (1976) já indicava tal perspectiva, na década de 1950, ao considerar como papel do ensino da Sociologia munir o estudante de instrumentos de análise objetiva da realidade social, além de sugerir-lhe pontos de vista com os quais pudessem compreender seu tempo e normas e construir sua atividade na vida social.

Faz-se necessário, ainda, chamar a atenção para o fato de que somente um professor devidamente licenciado tem condições de desenvolver as potencialidades da Sociologia de forma adequada, assim como devem ser licenciados nas suas respectivas áreas de atuação os profissionais que ministram as demais disciplinas.

\section{CONSIDERAÇÕES FINAIS}

Buscamos aqui examinar a BNCC (2019), observando e discutido como as Ciências Sociais podem colaborar para criar condições para que as competências sejam desenvolvidas pelos alunos do Ensino Médio. Destacamos que a Sociologia, por sua histórica presença intermitente no currículo escolar, acaba tendo sua manutenção no Ensino Médio fragilizada.

A obrigatoriedade da Sociologia no currículo do Ensino Médio brasileiro é resultado de um amplo movimento que envolveu diversos atores sociais nas discussões que envolveram as normativas e diretrizes marcadas por um embate entre uma visão "disciplinar" e "desdiciplinar". A maior conquista desse movimento deu-se, em 2008, com sua reintrodução no currículo do Ensino Médio brasileiro. Ganhos substantivos foram alcançados a partir de então, seja ligados à docência ou/e ao subcampo de pesquisa, sendo, contudo, ameaçados a partir da Reforma do Ensino Médio, de 2017. Esta, por sua vez, levou a aprovação da BNCC, em 2019, a qual se apresenta como desafio ao ensino das diversas disciplinas escolares, inclusive a Sociologia.

O retorno ao currículo com tendências de desdisciplinarização parece-nos ser um retrocesso aos anos de 1990 que acreditávamos ter sido superado no ano de 2008, quando a Sociologia e Filosofia foram incluídas nominalmente como componentes curriculares obrigatórios na LDB (1996).

Com a BNCC, o ensino-aprendizagem voltou-se ao "desenvolvimento de competências e habilidades" e cabe, nesse contexto, evidenciarmos de quais maneiras as Ciências Sociais podem colaborar para tal desenvolvimento, embora não apenas limitadas a ele. Ao demonstrarmos tais 
maneiras, torna-se evidente a importância de sua presença enquanto componente disciplinar, isso por suas particularidades teórico-metodológicas. Importa destacar que a manutenção da presença das Ciências Sociais no currículo do Ensino Médio, sua forma e carga-horária a ela destinada dependerá das disputas que se darão junto às Secretarias Estaduais de Educação que estão - orientadas pela BNCC - em processo de restruturação curricular. O fato é que a Reforma está posta, não será fácil revertê-la a curto e médio prazo, nos resta pensar caminhos para mitigar seus efeitos negativos. Estamos certos que a "desdisciplinarização" é um retrocesso que, se efetivado, trará impactos negativos sobre a qualidade do ensino.

Ao longo de nossa análise das competências trazidas pela BNCC (2019), identificamos que elas dialogam diretamente com as contribuições que as Ciências Sociais podem trazer aos alunos do Ensino Médio, o que evidencia a necessidade de sua manutenção e ampliação nesse nível de ensino, bem como maiores investimentos na formação docente, a fim de que todas as potencialidades dessa disciplina possam ser devidamente exploradas. Nota-se que tais competências, para serem atingidas, não demandam um currículo "desdisciplinarizado", o qual irá tornar o ensino médio mais superficial, distante ainda mais do que cada Ciência vem produzindo, implicando em maior distanciamento entre universidade e escola, saber científico e saber escolar.

Temos ciência de que a Educação é um processo contínuo e multifacetado, não cabendo a uma disciplina isoladamente assumir sua responsabilidade de alcançar os objetivos propostos nos documentos orientacionais. Ainda que a Sociologia Escolar seja capaz de colaborar para "o progresso social" (FERNANDES, 1976), entendemos que o aprendizado não promoverá, necessariamente, mudança linear da realidade social ou do sujeito que a interpreta, como bem destacou Mota (2005).

\section{REFERÊNCIAS}

AGUIAR, Marcia Angela da S. Política Educacional e a Base Nacional Comum Curricular: o processo de formulação em questão. Currículo sem Fronteiras, v. 18, n. 3, p. 722-738, set./dez. 2018. Disponível em: <https://www.curriculosemfronteiras.org/vol18iss3articles/aguiar.pdf >. Acesso em: 16 mar. 2020.

ALVES, Maria Alda de Sousa; RÖWER, Joana Elisa. Narrativas de si no espaço escolar, juventudes e ensino de Sociologia. Cadernos da Associação Brasileira de Ensino de Ciências Sociais. v.2, n.2, p.95-108, jul./dez., 2018. Disponível em: < https://abecs.com.br/revista/index.php/cabecs/article/view/137/102>. Acesso em: 16 mar. 2020.

AZEVEDO, Gustavo Cravo de. Sociologia no ensino médio: uma trajetória político-institucional (19822008). Dissertação de mestrado. Programa de Pós-Graduação em Ciência Política da Universidade Federal Fluminense. 2014.

BAUMAN, Zigmunt.; MAY, Tim. Aprendendo a pensar com a sociologia. Rio de Janeiro: Jorge Zahar Editor, 2010.

BODART, Cristiano das Neves; MARCHIORI, Cassiane da C. Ramos. (2015). Fundamentos do ensino de sociologia católica em uma escola normalista pública em 1935. Caderno Eletrônico de Ciências Sociais, Vitória, v. 3, n. 2, p. 18-38, 2016. Disponível em: <http://periodicos.ufes.br/cadecs/article/view/13653>. Acesso em: 10 mar. 2020.

; CIGALES, Marcelo Pinheiro. Ensino de Sociologia no Brasil (1993-2015): um estado da arte na pós-graduação. Revista de Ciências Sociais: RCS, Fortaleza, v. 48, n. 2, p. 256-281, 2017. Disponível em: < http://www.periodicos.ufc.br/revcienso/article/view/19500>. Acesso em: 10 mar. 2020.

; SAMPAIO-SILVA, Roniel. Quem leciona Sociologia após 10 anos de presença no Ensino Médio brasileiro? In: BODART, Cristiano das Neves; LIMA, Wnderson Luan dos Santos. O ensino de Sociologia no Brasil, vol.1. Maceió: Editora Café com Sociologia, 2019, pp. 33-58.

; TAVARES, Caio dos Santos. Quando o assunto é Sociologia escolar: estado da arte nos periódicos de estratos superiores nas áreas de Ciências Sociais, Educação e Ensino. Revista de Ciências 
Sociais. Fortaleza, v. 51, n. 1, mar./jun., p. 353-396, 2020. Disponível em: < http://www.periodicos.ufc.br/revcienso/article/view/31297>. Acesso em: 16 jun. 2020.

BRASIL. Base Curricular Nacional do Ensino Médio - Ensino Médio. Brasília: Ministério da Educação, 2019. Disponível em: <

http://portal.mec.gov.br/index.php?option=com_docman\&view=download\&alias=85121-bncc-ensinomedio\&category_slug=abril-2018-pdf\&ltemid=30192 >. Acesso em: 10 mar. 2020.

. Decreto n. 16.782-a, de 13 de janeiro de 1925. Estabelece o concurso da União para o ensino secundário, organiza o Departamento Nacional do Ensino, reforma o ensino secundário e o superior e dá outras providencias. 1925. Disponível em: < http://www.planalto.gov.br/ccivil_03/decreto/19101929/D16782a.htm>. Acesso em: 10 mar. 2020.

. Decreto n. 981 - de 8 de novembro de 1890. Approva o Regulamento da Instrucção Primaria e Secundaria do Districto Federal. 1890. Disponível em: < https://www2.camara.leg.br/legin/fed/decret/1824-1899/decreto-981-8-novembro-1890-515376publicacaooriginal-1-pe.html>. Acesso em: 10 mar. 2020.

. Decreto-lei n.4.244 de 9 de abril de 1942. Lei orgânica do ensino secundário. 1942. Disponível em: < https://www2.camara.leg.br/legin/fed/declei/1940-1949/decreto-lei-4244-9-abril-1942-414155publicacaooriginal-1-pe.html>. Acesso em: 10 mar. 2020.

. Lei n. 13415 de 16 de fevereiro de 2017. Lei de Reforma do Ensino Médio. Médio. Brasília, 2020. Disponível em: <http://www.planalto.gov.br/ccivil_03/_Ato2015-2018/2017/Lei/L13415.htm>. Acesso em: Acesso em: 16 mar. 2020.

. MEC, Ministério da Educação e Cultura. Organização Curricular Nacional-Sociologia. Brasília, 2006. Disponível em:< http://portal.mec.gov.br/seb/arquivos/pdf/book_volume_03_internet.pdf>. Acesso em: 08 mar. 2020.

. Medida Provisória n. 746 de setembro de 2016. Brasília, 2016. Disponível em: <https://www.congressonacional.leg.br/materias/medidas-provisorias/-/mpv/126992>. Acesso em: 16 mar. 2020.

. Ministério da Educação. Lei no 9.394, de 20 de dezembro de 1996. Estabelece as Diretrizes e Bases da Educação Nacional (LDB). Diário Oficial da União. Brasília, no 248, 23/12/1996. 1996. Disponível e: < http://www.planalto.gov.br/ccivil_03/leis/L9394.htm>. Acesso em: 08 mar. 2020.

. Ministério da Educação. Parâmetros Curriculares Nacionais (PCN's) para o Ensino Médio. Brasília, 2000a. Disponível e: < http://portal.mec.gov.br/seb/arquivos/pdf/blegais.pdf> Acesso em: 08 mar. 2020.

- Ministério da Educação. Parâmetros Curriculares Nacionais para o Ensino Médio (PCNEM): Ciências Humanas e suas tecnologias. Brasília, 200ob. Disponível em: <http://portal.mec.gov.br/seb/arquivos/pdf/cienciah.pdf> . Acesso em: 08 mar. 2020.

. Projeto de Lei 3.178/97. Disponível em: < https://www.camara.leg.br/proposicoesWeb/prop_mostrarintegra;jsessionid=AE3C43826A98BC49100A 97B7734B5C96.node2?codteor=1130709\&filename=Avulso+-PL+3178/1997>. Acesso em: 08 mar. 2020.

. Projeto de Lei Federal no 1641/2003. Dispõe sobre a obrigatoriedade das disciplinas de Sociologia e Filosofia no Ensino Médio. Brasília, 2003. Disponível em:< http://www.camara.gov.br/proposicoesWeb/fichadetramitacao?idProposicao=127294> Acesso em: 08 mar. 2020.

CEB/CNE. Câmara de Educação Básica do Conselho Nacional de Educação/Conselho Nacional de Educação. Parecer CNE n. 5/97. Proposta de Regulamentação da Lei no 9.394/96. 1996. Disponível em: < http://www.crmariocovas.sp.gov.br/pdf/diretrizes_p0291-0305_c.pdf>. Acesso em: 10 mar. 2020.

CEB/CNE. Câmara de Educação Básica do Conselho Nacional de Educação/Conselho Nacional de Educação. Resolução CEB n. 3, de 26 de junho de 1998. Institui as Diretrizes Curriculares Nacionais para o 
ISSN $1983-1579$

Doi: 10.22478/ufpb.1983-1579.2020v13n1.51194

http://periodicos.ufpb.br/ojs2/index.php

Ensino Médio. 1998. Disponível em: < http://portal.mec.gov.br/cne/arquivos/pdf/rceb03_98.pdf>. Acesso em: 10 mar. 2020.

CEB/CNE. Câmara de Educação Básica do Conselho Nacional de Educação/Conselho Nacional de Educação. Parecer n. CEB 15/98. Diretrizes Curriculares Nacionais Para O Ensino Médio. 1998. Disponível em: < http://portal.mec.gov.br/seb/arquivos/pdf/Par1598.pdf >. Acesso em: 10 mar. 2020. >. Acesso em: 10 mar. 2020.

COAN, M. A Sociologia no Ensino Médio, o Material Didático e a Categoria Trabalho. 2006. Dissertação de Mestrado. Centro de Educação. Universidade Federal de Santa Catarina. Florianópolis, 2006.

CORTI, Ana Paula. Política e significantes vazios: uma análise da Reforma do Ensino Médio de 2017. Educação em Revista, Belo Horizonte, v.35, p.1-20, 2019. Disponível em:

<http://www.scielo.br/scielo.php?pid=S0102-46982019000100425\&script=sci_arttext> Acesso em: 01 mar. 2020.

FEIJÓ, Fernanda. Ciências Sociais no Ensino Médio: pensando a Sociologia para uma formação democrática. In: BODART, Cristiano das Neves; LIMA, Wanderson Luan dos Santos (Org.). O ensino de Sociologia no Brasil, vol.1. Maceió: Editora Café com Sociologia, 2019. pp. 85-112.

. Quando o parlamento jovem torna-se parte da aula de Sociologia do Ensino Médio que visa a Educação Política. In: BODART, Cristiano das Neves (Org.). O ensino de Sociologia e de Filosofia. Maceió: Editora Café com Sociologia, 2020. pp. 43-80.

FERNANDES, Florestan. A Sociologia no Brasil. Petrópolis: Editora Vozes, 1976.

FERREIRA, Walace Ferreira; SANTANA, Diego Cavalcanti de. A Reforma do Ensino Médio e o Ensino de Sociologia. Revista Perspectiva Sociológica, Rio de Janeiro, n. 21, $1^{\circ}$ sem. p. 41-53. 2018, Disponível em: <https://cp2.g12.br/ojs/index.php/PS/article/view/1740>. Acessado em: 08 mar. 2020.

FERRETTI, Celso João. A reforma do Ensino Médio e sua questionável concepção de qualidade da educação. Estudos avançados, São Paulo, v. 32, n. 93, p. 25-42, Ago., 2018. Disponível em: <http://www.scielo.br/scielo.php?script=sci_arttext\&pid=S0103-40142018000200025\&lng=en\&nrm=iso>. Acessado em: 08 mar. 2020.

FIGUEIREDO, Elpídio de Abreu e Lima. Educação Moral, Noções de Sociologia e Direito Usual. Rio de Janeiro: Typ. do Jornal do Commercio, de Rodrigues \& C. 2017.

MILLS, C. W. A Imaginação Sociológica. Rio de Janeiro: Zahar Editores, 1965.

GUELFI, Wanirley Pedroso. A Sociologia como disciplina escolar no Ensino Secundário brasileiro (19251942). 2001. 194f. Dissertação (Mestrado em Educação)-Universidade Federal do Paraná, Curitiba, 2001.

LAHIRE, Bernard. Viver e interpretar o mundo social: para que serve o ensino da Sociologia? Revista de Ciências Sociais, Fortaleza, v. 45, n. 1, p. 45-61, jan./jun. 2014. Disponível em: < http://www.rcs.ufc.br/edicoes/v45n1/rcs_v45n1a2.pdf>. Acesso em: 16 mar. 2020.

MACHADO, Celso de Souza. O ensino de Sociologia na escola secundária: um levantamento preliminar. Revista da Faculdade de Educação, São Paulo, v. 13, n 1, p. 115-142, 1987. Disponível em: < http://www.revistas.usp.br/rfe/article/view/33382>. Acesso em: 16 mar. 2020.

MORAES, Amaury. Ensino de sociologia: periodização e campanha pela obrigatoriedade. Cadernos Cedes, Campinas, vol. 31, n. 85, p. 359-382, set./dez., 2011. Disponível em: <http://www.scielo.br/pdf/ccedes/v31n85/04v31n85.pdf>. Acesso em: 10 mar. 2020.

MOTA, Kelly Cristine Corrêa da Silva. Os lugares da sociologia na formação de estudantes do ensino médio: as perspectivas de professores. Revista Brasileira de Educação, Rio de Janeiro, n. 29, p. 88-107, Ago. 2005. Disponível em: < http://www.scielo.br/pdf/rbedu/n29/n29a08.pdf>. Acesso em: 16 mar. 2020. 
OLIVEIRA, Amurabi. Revisitando a história do ensino de Sociologia na Educação Básica. Acta Scientiarum: Education, Maringá, v. 35, n. 2, p.179-189, 2013a. Disponível em: < http://periodicos.uem.br/ojs/index.php/ActaSciEduc/article/view/20222>. Acesso em: 10 mar. 2020.

. A Antropologia no Ensino Médio. Caderno de Estudos Sociais. Recife, v.28, n.2, jul./dez. 2013b. Disponível em: <https://fundaj.emnuvens.com.br/CAD/article/view/27/40>. Acesso em: 16 mar. 2020.

O ensino de Sociologia e as Novas DCNEM. Educare et Educare. Cascavel, v.9 n.18 jul./dez. 2014. Disponível em: <http://e-revista.unioeste.br/index.php/educereeteducare/article/view/9290>. Acesso em: 10 mar. 2020.

OLIVEIRA, Natália Braga de; CARNEIRO, Silzane de Almeida. A educação em Direitos Humanos e a contribuição do ensino de Sociologia para a ação emancipatória. Revista Perspectiva Sociológica, Rio de Janeiro, n. 20, $2^{\circ}$ sem. p. 66-77, 2017. Disponível em: <https://www.cp2.g12.br/ojs/index.php/PS/article/view/1475/1069>. Acesso em: 16 mar. 2020.

SILVA, Ileizi Luciana Fiorelli; ALVES NETO, Henrique Fernandes, VICENTE, Daniel Vitor. A proposta da Base Nacional Comum Curricular e o debate entre 1988 e 2015. Ciências Sociais Unisinos, São Leopoldo, v. 51,n.3, p.330-342, set./dez. 2015. Disponível em: < http://revistas.unisinos.br/index.php/ciencias_sociais/article/view/csu.2015.51.3.10>. Acesso em: 08 mar. 2020.

Recebido em: 16/03/2020

Alterações recebidas em: 13/04/2020

Aceito em: 14/04/2020

Publicado em: 14/04/2020 